\title{
GEODETIC EVIDENCE FOR ACTIVE UPLIFT OF THE OLYMBUS MT, GREECE
}

\author{
Stiros S. ${ }^{1}$, and Triantafillides $\mathrm{P} .{ }^{1}$, and Chasapis A. ${ }^{2}$ \\ ${ }^{1}$ Department of Civil Engineering, University of Patras, 26500, Patras, stiros@upatras.gr, \\ ptriant@upatras.gr \\ ${ }^{2}$ I.G.M.E., Mesogion Str. 70, 11527 , Athens
}

\begin{abstract}
Repeated leveling data collected between 1964-1989 along a traverse crossing the Tempi Valley and the Olymbus Mt (Greece) domal uplift testify to a small, though significant (4-21 $\pm 1.2-$ $4.7 \mathrm{~mm}$ ) bulging of the central part of the traverse relative to its edges. In combination with coastal observations indicating land uplift at the eastern part of the traverse, as well as with structural and engineering geology observations excluding the possibility the overall pattern of observed displacements to reflect local instability effects, leveling data probably indicate a small amplitude domal uplift. The later is likely to reflect the continuation of the process responsible for the formation of the Olymbus-Ossa Mts, for uncovering of upper mantle rocks and for the impressive incision in the Tempi Valley. Furthermore, the lack of seismicity during the period covered by leveling data indicates that the Olymbus uplift is at least partly associated with aseismic processes.
\end{abstract}

\section{INTRODUCTION}

Mount Olymbus in northern Greece (Fig.1), famous from the ancient Greek mythology, has long been recognized as a "tectonic window", i.e. as a "hollow" in the earth's crust from which mantle rocks reach the surface (Vergely \& Mercier 1990, Fig.2a,b). This nearly domal uplift was probably very rapid, and responsible for the present days topography of the area, with Mt. Olymbus being the highest mountain in Greece, 2919m high (Katsambalos et al. 1997). The mechanism, timing, amplitude and rates of this uplift are, however, a matter of debate among investigators. Vergely and Mercier (1990) argue that the opening of the Olymbus tectonic window took place between Oligocene and Late Miocene, prior to the post-Upper Miocene extensional period; i.e. it was regarded as a compressional effect. Schermer (1990), on the contrary, associated the uplift of mantle rocks in the Olymbus with low-angle normal faults. Finally, on the ground of correlations of planation surfaces in a wider scale, Faugères (1975) proposed an about $2 \mathrm{~km}$ uplift and opening of the tectonic window in Pleistocene, while Psilovikos (1981) assigned a small part (10\%) of the total uplift (1800$2400 \mathrm{~m}$ ) to this period. While such geomorphological correlations remain dubious, there is indirect evidence that this uplift continued during the last few thousand or tens of thousand years and was partly, at least, associated with earthquakes.

1. The impressive incision of the Pinios river at the Tempi Valley (Fig.1), part of which occurred in Holocene (about $5 \mathrm{~m}$ after $6500 \mathrm{BC}$; Demitrack, 1986), can only be explained as a response of the Pinios river to the uplift of the area it is crossing: the erosion potential of the river was directed to downcutting, in order to preserve its flow (Mayer 1986, Stiros et al. 1999).

2. Holocene and Late Pleistocene raised shorelines along the Aegean coast (Stiros et al., 1994, Pirazzoli et al., 1996) indicate an active uplift of the Olymbus-Ossa and Pelion Ranges and the associated coastal zone.

3. Myths conveyed by ancient authors (Pindar, Pyth., 4.246, Herodotus 7.129) associate the opening of the Tempi Valley with earthquakes and their god, Poseidon.

Has this uplift continued in the last decades, i.e. in a period which is characterized by lack of seismicity in the Olymbus area (Papazachos \& Papazachou 1997)? An effort to answer this ques- 
tion is made in this article using repeated leveling data along a traverse crossing this tectonic window.

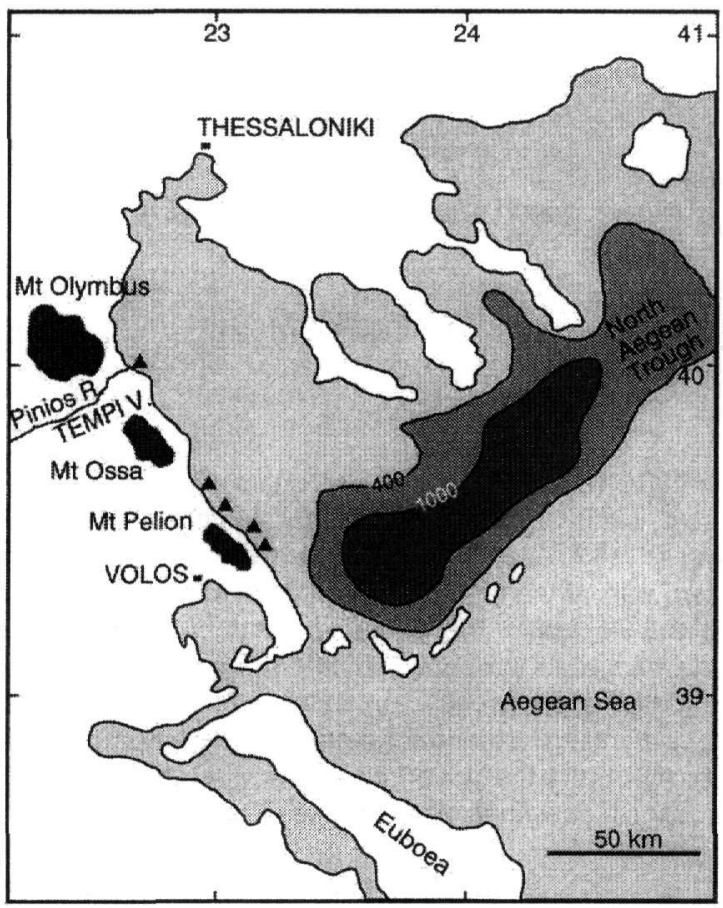

Figure 1. Location map. Dark shading inland indicates topography above $1000 \mathrm{~m}$ in Mt Olymbus, Ossa, Pelion. Triangles indicate areas with sign of Holocene coastal uplift.
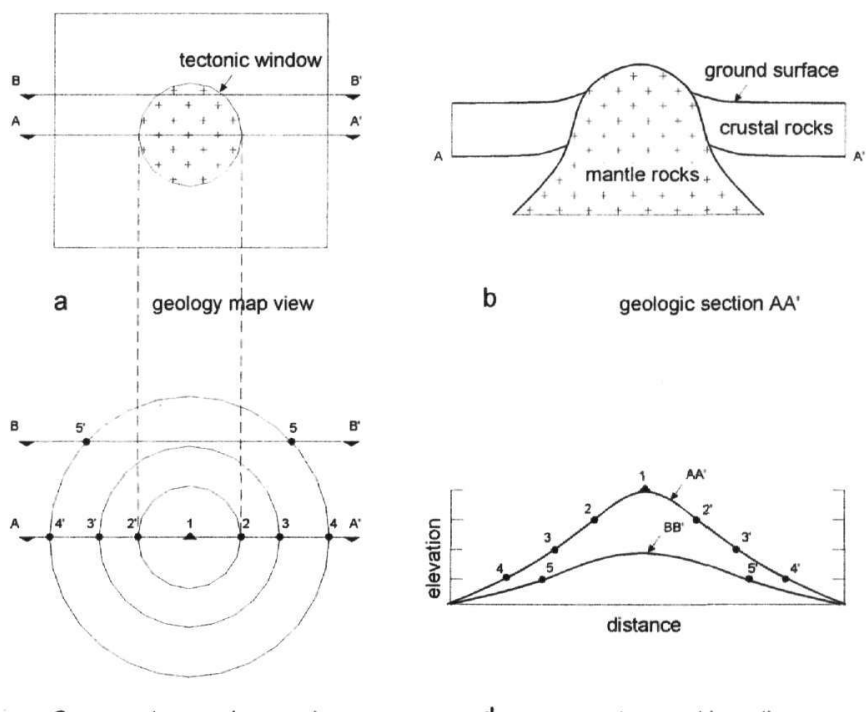

b

geologic section $\mathrm{AA}^{\prime}$

C topography map view

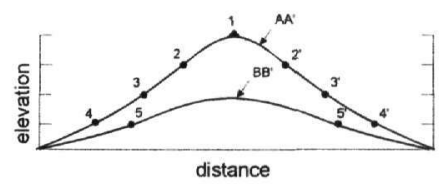

d

topographic sections

Figure 2. A cartoon to explain geology and topography in a tectonic window. The uplift of mantle rocks (crosses) has produced a surface bulge reflected in the local topography. Idealized elevation contours are shown in (c), while (d) shows topography cross-section along axes $A A^{\prime}$ and $B B^{\prime}$ in (c). 


\section{METHODOLOGY}

Vertical tectonic deformation in a domal uplift is not uniform, but variable; it takes its maximum amplitude approximately in the middle of the dome and dies away of it (Fig. 2). If the uplift (doming) is active, the topography profiles along any route crossing this dome during subsequent measurement periods should be different (Fig. 3a), and for each point the net uplift between the two periods would be the difference of elevations of the corresponding measurement periods (Fig. 3b). If measurements of elevation range are made relative to an assumed stable reference point away from the deforming area, the elevation changes would follow the pattern of the graph of Fig. $3 \mathrm{~b}$. This pattern of deformation (or of elevation changes) will be similar along all routes crossing the domal uplift (e.g. $\mathrm{AA}^{\prime}$ or $\mathrm{BB}^{\prime}$ in Fig. $2 \mathrm{~b}$ ), and their only difference will be in the amplitude of the deformation; higher along route $\mathrm{AA}^{\prime}$, lower along route $\mathrm{BB}^{\prime}$, i.e. along routes crossing the center and margins of the relief, respectively (Fig. 3). Inversely, any elevation changes of the type of Fig.3b observed along any route crossing a dome would be evidence of domal uplift during the period of measurements. For small time-scale uplifts due to volcanic or tectonic effects, rates of uplift of the order of up to a few centimeters per year or more are not unusual (Dzurisin \& Yamashita 1987, Marshal et al. 1997). On the contrary, for major, long-lasting domal uplifts which originate from cumulated movements and lead to mountains, the average rate of their deformation is small, of the order of a fraction of $\mathrm{mm}$ per year, otherwise mountains higher than the Himalayas would characterize the Earth's surface.

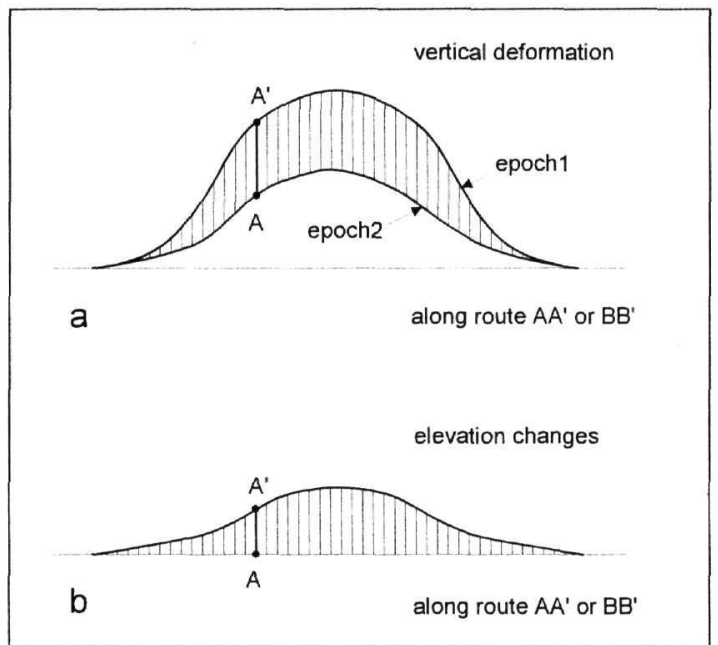

Figure 3. A cartoon to explain geology and topography in a tectonic window. The uplift of mantle rocks (crosses) has produced a surface bulge reflected in the local topography.

In the case of the Tempi Valley, the average Holocene uplift rate is of the order of $0.8 \mathrm{~mm} / \mathrm{yr}$, as can be deduced from the downcutting of the Pinios river (Demitrack 1986). Active uplifts with these rates may only be noticed and recorded using high accuracy repeated leveling data. Unfortunately, high accuracy leveling traverses have first, a very limited geographical distribution: they are confined to some major roads, and hence they may cross only the periphery of domal uplifts. And second, repeated measurements are very rare, mainly because of the cost of the field campaigns. Incidentally, repeated measurements of a leveling traverse crossing the Tempi Valley are available. These data are examined in this paper in order to identify whether they contain any signal that can provide information on a recent uplift of the Olymbus Mt. range.

\section{DATA}

A first order leveling traverse was established by the Hellenic Military Geographic Service in 1964 along the national road passing from the Tempi Valley, on a nearly flat terrain, mostly along a 
fluviatile terrace. This traverse is the only one crossing the metamorphic rocks of the OlymbusOssa-Pelion ranges (Fig.1). Measurement specifications of this survey are shown in Table 1. Such specifications permit an accuracy of $0.5 \sqrt{S \mathrm{~mm}}$ ( $\mathrm{S}$ is the section distance in $\mathrm{km}$ ), a result confirmed by the adjustment of the regional $1^{\text {st }}$ order National Leveling Network (Mylona-Kotrogianni, 1990).

Part of this traverse, between benchmarks (BM) 112 and 130, approximately $18 \mathrm{~km}$ long, was remeasured in 1988/89 by the IGME (Institute of Geology and Mineral Exploration, Athens) surveying team. 16 out of the $19 \mathrm{BM}$ originally established were found and reoccupied. These are the only surviving BMs that were found in the vicinity of the Tempi Valley; all other nearby BMs were probably destroyed by road works. Measurement specifications for this second survey are also shown in Table 1. A typical, a priori accuracy of $1.0 \sqrt{\mathrm{S}} \mathrm{mm}$ is expected for such a survey.

Table 1. Specifications of 1964 and 1988/89 surveys (partly after Stiros and Rondogianni, 1985) S indicates section length.

\begin{tabular}{|c|c|c|}
\hline & 1964 Survey & 1988/89 Survey \\
\hline Instrument standards & $\begin{array}{l}\text { Wild N3 or Zeiss NiOO4 level } \\
\text { Invar scale rods with struts and foot- } \\
\text { plates }\end{array}$ & $\begin{array}{l}\text { Automatic geodetic levels and invar } \\
\text { scale rods with struts and footplates }\end{array}$ \\
\hline Field procedures & $\begin{array}{l}\text { Double run, forward and backward } \\
\text { by different parties and instruments, } \\
\text { with at least } 3 \text {-day period between }\end{array}$ & Double run \\
\hline Section length (S) & $0.8-1.3 \mathrm{~km}$ & $0.8-1.3 \mathrm{~km}$ \\
\hline Mean length of sight & $20 \mathrm{~m}$ & $30 \mathrm{~m}$ \\
\hline Max length of sight & $25 \mathrm{~m}$ & $30 \mathrm{~m}$ \\
\hline $\begin{array}{l}\text { Maximum difference in lengths for- } \\
\text { ward and backward sights per setup }\end{array}$ & $0.2 \mathrm{~m}$ & $10 \mathrm{~m}$ \\
\hline Per section (cumulative) & $0.5 \mathrm{~m}$ & $10 \mathrm{~m}$ \\
\hline $\begin{array}{l}\text { Maximum Closures } \\
\text { Section, forward and backward }\end{array}$ & $1(\mathrm{~S})^{1 / 2} \mathrm{~mm}$ & $2(\mathrm{~S})^{1 / 2} \mathrm{~mm}$ \\
\hline $\begin{array}{l}\text { Accuracy of height difference be- } \\
\text { tween directly connected bench- } \\
\text { marks }\end{array}$ & $0.5(\mathrm{~S})^{1 / 2} \mathrm{~mm}$ & $1.0(\mathrm{~S})^{1 / 2} \mathrm{~mm}$ \\
\hline
\end{tabular}

\section{RESULTS}

For each survey observed elevation changes between consecutive benchmarks (BM) were used to compute elevation changes of each benchmark relative to BM 130; results are shown in graph form in figure 4. This graph seems to consist of four segments: (1) a western segment between BM 130 and 126 characterized by fluctuations in the change of relative elevation of BMs with an amplitude of up to $7.5 \mathrm{~mm}$; (2) a central segment between BM126 and RC, characterized by trivial apparent relative elevation changes between BMs; (3) a segment between BM RC and 115 characterized by an apparent relative elevation change of approximately $20 \mathrm{~mm}$, and (4) an eastern segment about $2.5 \mathrm{~km}$ long, between BM 115 and BM 112, practically characterized by a lack of relative elevation changes between BMs (Fig. 4).

The a priori, typical accuracy of computed relative elevation differences between the two surveys, considered to be uncorrelated, is $\sqrt{\left(0.5^{2}+1^{2}\right)} \cdot \sqrt{\mathrm{S}} \mathrm{mm}$ or $1.1 \sqrt{\mathrm{S}} \mathrm{mm}$. This indicates that the expected standard error of the elevation change of the one edge of the traverse relative to the other, $18 \mathrm{~km}$ away, is of the order of $4.7 \mathrm{~mm}$, and about $3 \mathrm{~mm}$ from the edges relative to the middle of the traverse (Fig.4). Consequently, apparent elevation changes of BMs of the second segment (BM126-RC) and of the fourth segment (BM115-112) are slightly higher and several times higher, respectively, than their typical standard errors. This indicates are at least some of the observed apparent elevation changes relative to BM130 are statistically significant against random errors. 


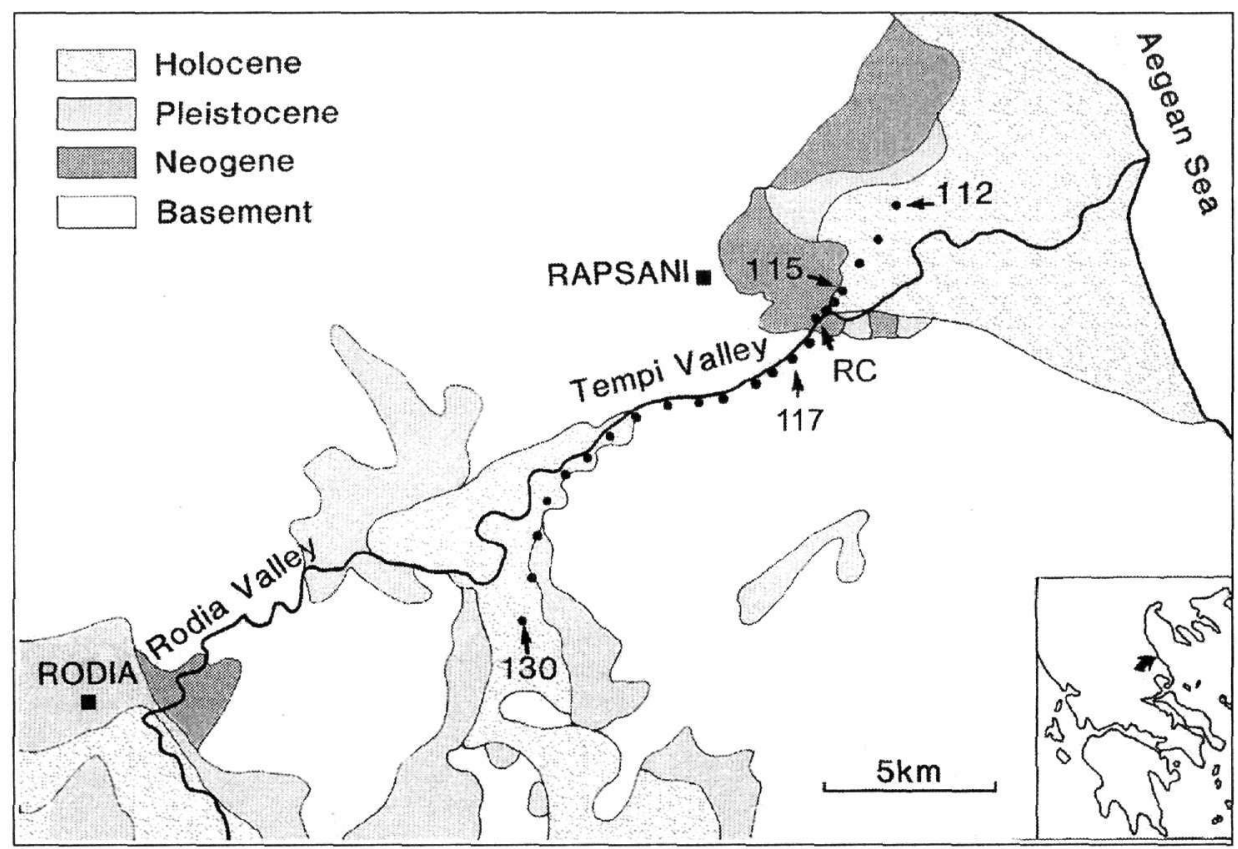

Figure 4. Location of benchmarks and geology in the Tempi area. Partly after (Katsikatsos et al (?))

Furthermore, the similarity of measurement procedures in both surveys, the relatively small (18 $\mathrm{km}$ ) length of the section studied and the flat terrain along the leveling route (a nearly horizontal fluviatile terrace) make unlikely the existence of systematic errors usually affecting certain repeated leveling data: This is the case of long traverses measured with different procedures (usually a major change in the level-to-rod sighting distance) and along an anomalous terrain introducing important cumulative errors. The latter are mainly due to reflection effects of the lower strata and can noticed as a correlation between computed relative elevation changes and topography (Reilinger \& Brown 1981, Stein 1981, Strange 1981).

\section{DISCUSSION}

Among the four segments in which the leveling traverse was divided, only segment 1 (BM130126 ) is characterized by fluctuations in the apparent elevation change of the corresponding BMs relative to BM 130. However, in spite of their significant amplitude (7.5mm for BM 127), these fluctuations are very small-wavelength effects (reversals in the sense of apparent movements are observed along consecutive BMs) and they can definitely reflect local effects only. On the contrary, observed elevation changes in segments 2 (between BM 126 and RC), 3 (between BM RC and 115) and 4 (between BM 115 and 112) are nearly uniform or systematic, reflecting longer wavelength effects, while segments 2 and 4 , seem to correspond to rigid body movements. Therefore, adopting the technique used in time-series analyses of geodetic displacement data (Wdowinski et al. 1997) we may replace segments 2 and 4 with the corresponding mean values, $3.2 \pm 1.0 \mathrm{~mm}$ and $-18.1 \pm 0.6 \mathrm{~mm}$ respectively. Thereafter we may calculate their offset and its precision, $21.3 \pm 1.2$ $\mathrm{mm}$, applying the law of propagation of errors (summing variances).

Consequently, in spite of the small amplitude of the observed displacements, there is evidence of significant relative dislocations for the majority of BMs. Among them, BMs 125 to 119 are founded on basement rocks, while BMs $129,128,126,125$ and 116-118 are founded on a thin veneer of Pleistocene and Neocene formations covering basement rocks; consequently, all these BMs seem to be free of local instability effects characterizing unconsolidated and unstable terrains, especially since the topography gradient along the traverse is nearly zero. For this reason the possibility these BMs to reflect significant (a few $\mathrm{mm}$ or more) subsidence due to consolidation of loose 
material, etc. or other ground instability effects should be rejected, especially since such effects would have been recognized from signs of failure of the roadbed.

In conclusion, the available data reveal an about $21.3 \pm 1.2 \mathrm{~mm}$ offset of the central part of the traverse relative to the eastern part. This is probably a pessimistic estimate, because, if the technique used in time series analysis of displacements is adopted here, and the four segments are replaced by regression lines, uncertainty margins will be reduced, for standard errors of individual BMs will be replaced by the errors of their mean, which is significantly smaller (Wdowinski et al. 1997).

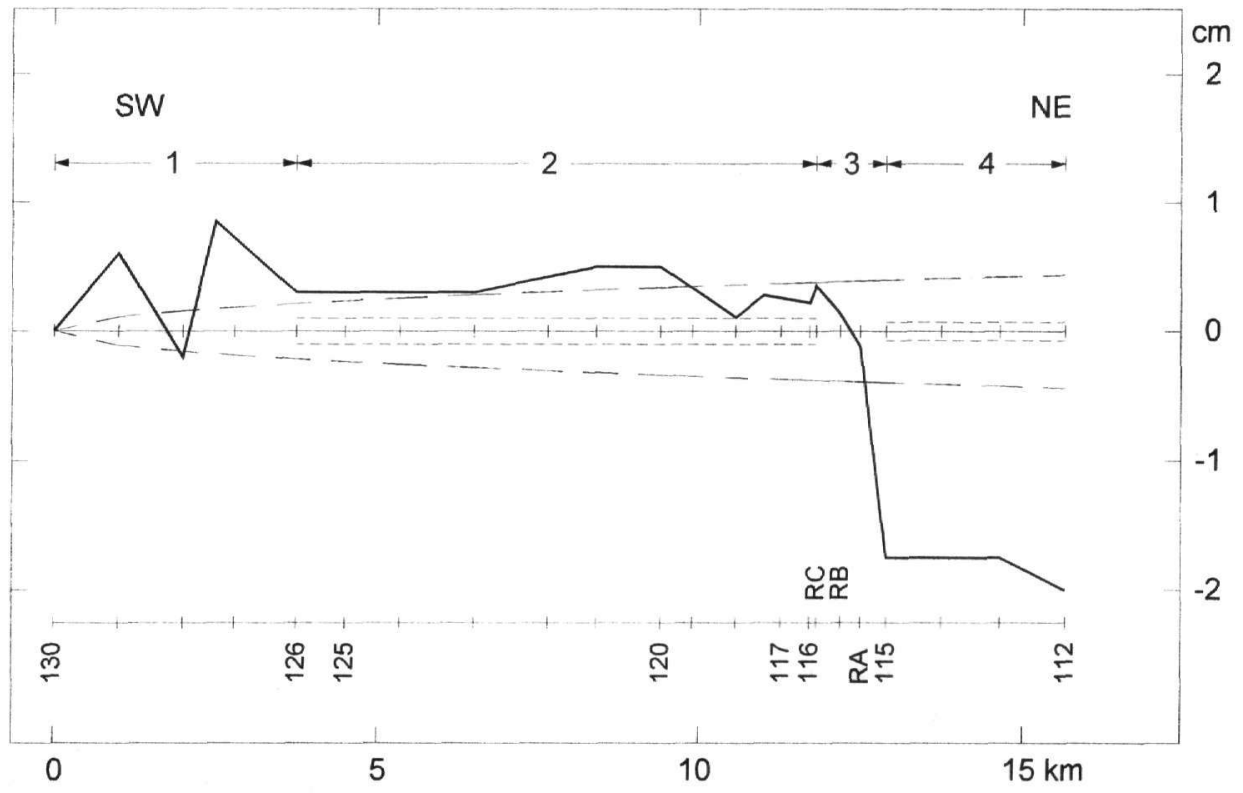

Figure 5. Elevation changes deduced from comparison of 1960 and $1988 / 89$ spirit leveling data relative to Benchmark (BM) 130. Observed displacements (continuous line) are plotted versus distance from BM 130, along an axis best fitting to the leveling route(i.e. along a distance smaller than the length of the leveling route, $\sim 18 \mathrm{~km}$ ). Dotted lines indicate a priori, typical errors, dash-dotted lines errors calculated for certain individual segments.

The offset between segments reflects either an uplift of the central part relative to the eastern, or a subsidence of the eastern relative to the central part. At first sight, the second case seems more likely: subsidence of BMs founded on alluvium may indicate either compaction of unconsolidated material, or normal faulting, i.e. the type of faulting which is widespread in the region. However, such explanations are not easy to be accepted. Three BMs spanning a distance of about $2.5 \mathrm{~km}$ show a rather uniform subsidence, and this excludes the possibility of local ground instability. Furthermore, there is no sign of active normal faulting between BM117 and 115 to explain the observed relative subsidence, while the amplitude of normal faulting could not have been nearly uniform along this distance. On the contrary, raised Holocene marine features at the southern bank of Penios River (Fig. 6) indicate a coastal (land) uplift similar to what has been observed farther south (Stiros et al. 1994, Pirazzoli et al. 1996). Consequently, it is more reasonable to suggest that the relative offset seen in leveling data are likely to indicate an uplift of the basement rocks of the Tempi valley than extension-related subsidence which controls plain evolution in Thessaly during Quaternary (Caputo et al. 1991). This interpretation is consistent with N and NE-tilted sediments along fault-controlled range fronts north of the Rodia Valley (Caputo 1992). 

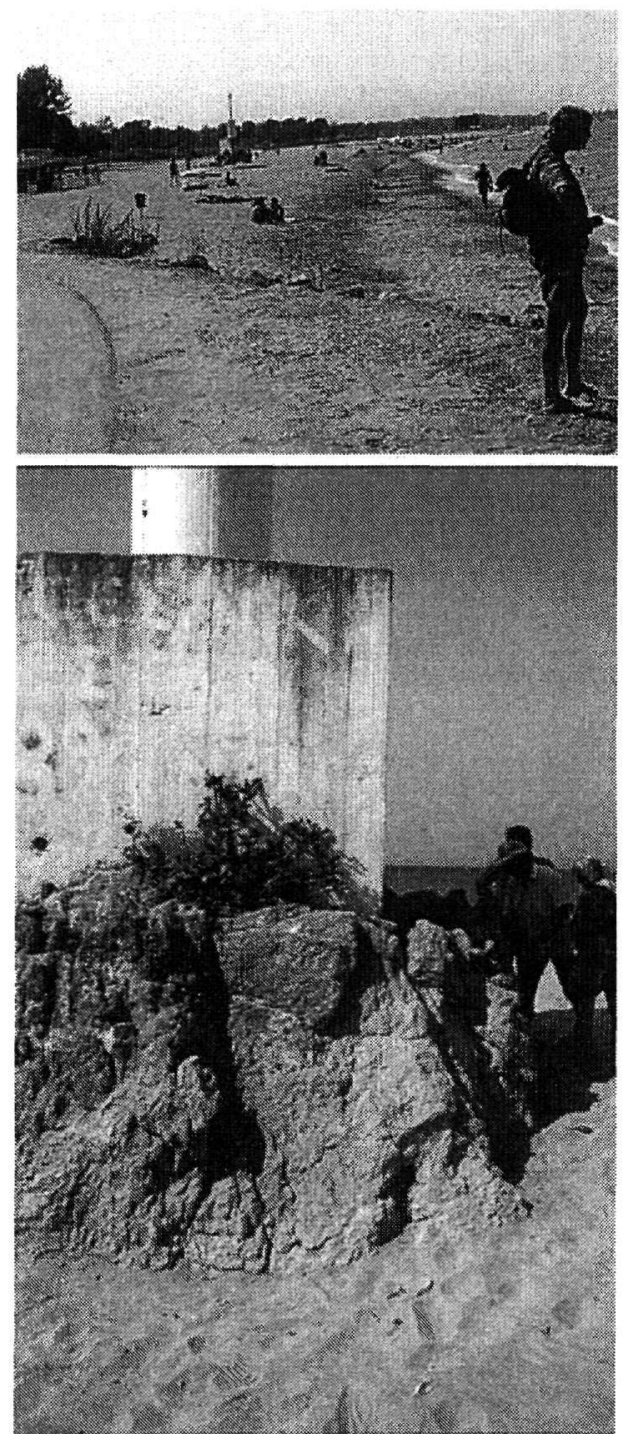

Figure 6. The lighthouse at Stomion at the south bank of the Pinios River (slightly visible behind the lighthouse in the upper photo), silted in the last decades, is built on a rock marked with signs of marine organisms, drillings of Lithophaga lithophaga and calcitic algal encrustations (photo on the right). These remains of a relatively lower sea level have not been dated, but seem to be coeval with similar features, characterizing the coast farther south (see Stiros et al., 1994; Pirazzoli et al., 1996).

\section{GEOMORPHOLOGICAL AND TECTONIC IMPLICATIONS}

Although the amplitude of the signal of relative elevations changes along the Tempi valley is above the error margin $(1.2-4.7 \mathrm{~mm})$ in the available leveling data, it is certainly small $(4-21 \mathrm{~mm})$. However, the relative offset of at least two segments of the leveling traverse (segments 2 and 4) are well constrained by a number of consistent observations (sets of benchmarks with nearly uniform relative elevation changes) and rather indicative of a tectonic signal of uplift of the OlymbusOssa massif relative to its edges. Consequently, there is evidence for land bulging in the central part of the leveling traverse. 
As is depicted in figure 3 , this pattern of displacement is rather indicative of a domal uplift with an average amplitude of $0.8 \mathrm{~mm} / \mathrm{yr}$. Interestingly, this rate is of the same order of magnitude with the Late Holocene rate deduced by Demitrack (1986) from the incision of the Pinios River, but this might be only a coincidence. However, as is explained in figure 2, the observed rate of doming corresponds to a route crossing the periphery of the dome, and not its centre; therefore, the corresponding maximum rate of uplift of Olymbus should be much higher, though of unknown amount, given the lack of a precise control of the long-term uplift (see above).

Another implication of the above results is that this recent uplift occurred during a period marked by absence of seismicity in the Olymbus area (see Papazachos \& Papazachou 1997, for instance). Since coastal change provide unambiguous evidence of seismic uplifts which have contributed in the present-day morphology of the region (Stiros et al. 1994, Pirazzoli et al. 1996), geodetic evidence for uplifts though of small amplitude, probably indicates that a combination of seismic and non-seismic effects are responsible for the uplift of the Olymbus and the Ossa Ranges. This result is not surprising, for the uplift of Northern Peloponnese seems also to have been a result of combination of seismic and aseismic effects (Stiros 1988).

On the other hand, geodetic evidence seems to support a conclusion deduced on the base of coastal data: that at least part of the uplift of the Olymbus and Ossa Mt Ranges reflects an extensional rather than a compressional effect, since their evolution continues during the Holocene, characterized by normal faulting in the wider region (Stiros et al. 1994).

\section{CONCLUSIONS}

Spectacular, Late Holocene and long-term incision of the Tempi and other Pinios River valleys (Demitrack 1986), exhumation of mantle rocks and present-day, high topography (Vergely \& Mercier 1990, Schermer 1990), Holocene coastal uplift and geodetic bench mark displacements seem to be conjugate effects, providing evidence of a large scale uplift, the details of which are poorly understood. Geodetic evidence for active, small-scale doming, in particular, also indicates that this uplift is active and associated with a combination of aseismic and seismic effects.

\section{ACKNOWLEDGEMENTS}

We thank the Hellenic Military Geographic Service for collaboration and information. Funding for the 1988/89 field survey was provided by the Active Geodynamics Project-8661704 of IGME.

\section{REFERENCES}

Caputo R., 1992. The Rodia fault system: An interactive complex shear zone (Larissa plain, central Greece). Bull. of the Geological Society of Greece, XXVIII/1, 447-456.

Caputo R., Pavlides S., 1991. Late Cainozoic geodynamic evolution of Thessaly and surroundings (centralnorthern Greece). Tectonophysics, 223, 339-362.

Demitrack A., 1986. The Late Quaternary geologic history of the Larissa plain, Thessaly, Greece: Tectonic, climatic and human impact of the landscape. PhD thesis, Stanford University, $133 \mathrm{pp}$.

Dzurisin D. \& Yamashita K. 1987. Vertical surface deformation at Yellowstone Caldera, Wyoming, 1976-1986. J. Geophys. Res., 92, 1353-13766.

Faugeres L., 1975. Recherches geomorphologiques en Grece septentrionale. These, Geogr, Univ. Paris IV (in French).

Katsambalos K., Badellas A. \& Savvaidis P., 1997. Determination of the elevation of Olymbus Mt. peaks based on modern technology. Olymbus, 101, 13-15.

Katsikatsos G., Migiros G. \& Papazeti, E., (?). Geological Map of Greece, 1:50,000 scale, Rapsani sheet. IGME, Athens.

Mayer L. 1986. Tectonic geomorphology of escarpments and mountain fronts. Active tectonics, National Academy Press, Washington DC, 125-135.

Marshall G.A., Langbein J., Stein R., Lisowski M. \& Svarc J., 1997. Inflation of Long Valley caldera, California, Basin and Range strain, and possible Mono Craters dike opening from 1990-94 GPS surveys. Geophysical Research Letters, 24, 9, 1003-1006. 
Mylona-Kotrogianni H. 1990. The $1^{\text {st }}$ order leveling net of Greece. Bull. of the Hellenic Military Geographic Service, 138, 1-26 (in Greek).

Papazachos B. \& Papazachou C., 1997. The earthquakes of Greece. Zitis Publisher, Thessaloniki, 304 pp.

Pirazzoli P., Laborel J., \& Stiros S., 1996. Earthquake clustering in the Eastern Mediterranean during historical times. Journal of Geophysical Research, 101, B3, 6083-6097.

Psilovikos A. 1981. Geomorphological, morphogenetic, tectonic, edimentological and climatic processes that led to the formation and evolution of composite alluvial fans in Olymbus Mt. PhD Thesis, University of Thessaloniki (in Greek).

Reilinger R. \& Brown L., 1981. Neotectonic deformation, near-surface movements and systematic errors in U.S. releveling measurements: Implications for earthquake prediction. Earthquake prediction: An international Review, D. Simpson and P. Richards, eds., AGU Maurice Ewing Series 4, 422-440.

Savage J.C. \& Lisowski M., 1984. Deformation in the White Mountain Seismic Gap, California-Nevada, 19721982. Journal of Geophysical Research, 89, B9, 7671-7687.

Schermer E. 1990. Mechanisms of blueschist creation and preservation in a A-type subduction zone, Mount Olymbos region. Greece. Geology, 18, 1130-1133.

Stein R. 1981. Discrimination of tectonic displacement from slope-dependent errors in geodetic leveling from Southern California, 1953-1979. Earthquake prediction: An international Review. D. Simpson and P. Richards, eds., AGU Maurice Ewing Series 4, 441-456.

Stiros S. 1988. Model for the Northern Peloponnesian (Central Greece) uplift. Journal of Geodynamics, 9, 199214.

Stiros S. \& Rondogianni T., 1985. Recent vertical movements across the Atalandi fault-zone (Central Greece). Pure and Applied Geophysics, 123, 837-848.

Stiros S.C., Pirazzoli P.A., Pomoni-Papaioannou F., Laborel J., Laborel F. \& Arnold M., 1994. Late quaternary uplift of the Olumbus - Pelion range coasts (Macedonia- Thessaly, Greece). Bull. of the Geological Society of Greece, XXX/1, 325-330.

Stiros S., Barkas N. \& Moutsoulas M., 1999. River erosion and landscape reconstruction in Epirus: methodology and results. In: G. Bailey et al., eds., "The Palaeolithic Archaeology of Greece and adjacent regions", London, 108-114.

Strange W. 1981. The impact of refraction corrections on leveling interpretations in Southern California. J. Geophys. Res., 86, B4, 2809-2824.

Vergely P. \& Mercier J., 1990. La fenetre metamorphique de l' Olympe (Macedoine, Grece): compression and extension Cenozoique. Bull. Soc. Geol. France (8)6, 819-.

Wdowinski S., Bock Y., Zhang J., Fang P. \& Genrich J., 1997. Southern California permanent GPS geodetic array: Spatial filtering of daily positions for estimating coseismic and postseismic displacements induced by the 1992 Landers earthquake. Journal of Geophysical Research, 102, B8, 18057-18070. 